\title{
Improving the collaboration between architects and energy consultants through design- integrated early BIM-tools
}

\author{
Alexander Hollberg ${ }^{1,2}$, Norman Klüber ${ }^{3}$, Matthias Götz ${ }^{4}$, Thomas Lichtenheld ${ }^{5}$, Philipp Hollberg ${ }^{5}$, \\ Alina Galimshina ${ }^{1}$, Guillaume Habert ${ }^{1}$ \\ ${ }^{1}$ ETH Zürich, Department of Civil, Environmental and Geomatic Engineering \\ ${ }^{2}$ Chalmers University of Technology, Department of Architecture and Civil Engineering \\ ${ }^{3}$ Fraunhofer Institute for Microstructure of Materials and Systems IMWS, Halle, Germany \\ ${ }^{4}$ Götz+Bilchev Architekten, Berlin, Germany \\ ${ }^{5} \mathrm{CAALA} \mathrm{GmbH}$, Munich, Germany
}

\begin{abstract}
There is a lack of optimization of buildings towards energy performance in early design stages in practice. Interviews with architects and energy consultants showed that one reason is the inefficient communication between these two groups. This paper investigates how a designintegrated early-BIM tool can improve the relation between architects and energy consultants to support an optimization process in early design stages and facilitate issuing energy performance certificates. Two case studies show that the early-BIM tool provides meaningful results for the architects involved and can reduce the input time for energy consultants by $50 \%$. Furthermore, the simple 3D model functions as boundary object between the two groups and supports the collaboration.
\end{abstract}

\section{Introduction}

Buildings are one of the biggest carbon emitters and are responsible for about $40 \%$ of the world's primary energy demand. At the same time buildings provide the biggest potential for cost-efficient reduction of greenhouse gas (GHG) emissions (UNEP SBCI 2009). In general, decisions made in the early phases of the design process, have the greatest influence, as they set general conditions for the subsequent design process (Paulson Jr. 1976). As such, the concept design phase has the highest influence on both operational energy demand (Hegger et al. 2007) and environmental impacts (Bogenstätter 2000). The early design phases are therefore ideal for optimization (Phase 1 and 2 in Figure 1). In the majority of building projects, especially in smaller housing projects, architects work alone in early design phases (Weytjens and Verbeeck 2010a). Large-scale architectural offices might have the ability to work in a design team together with energy and environmental specialists from early design on. However, in many European countries most architects work in small-scale offices (T'Jonck 2013; Hildebrand 2014; Goos 2017) and they largely rely on their own knowledge and expertise to make design decisions (Weytjens and Verbeeck 2010b; Meex, Knapen, and Verbeeck 2016).

The German fee structure for architects and engineers (HOAI) assigns the major part of the workload for energy consultants to phase 3 (see Figure 1 and Table 1). Phase 4 only consists of issuing the certificates needed for the building permit. However, in most cases in the German context, energy consultants are hired shortly before the building permit application when an energy performance certificate is needed (Phase 4 in Figure 1). Besides few exceptions, this is also the case in other national contexts (Alsaadani and De Souza 2016). When hired late (in phase 4), energy consultants can only check whether the legal requirements are met. It is late for optimising the building's performance, because changes to the design would be too costly. As such, the potential for reducing the energy demand and therefore GHG emissions cannot be exploited. In addition, the users of the building have higher operational costs that could be avoided.

As the energy performance requirements are tightened regularly, it becomes increasingly difficult to meet them. In case the building does not meet the required threshold, adaptions such as increased insulation or a different technical equipment are needed, leading to raised investment costs. Clearly, this is not in favour of the architects and their clients.

Table 1: Definition of tasks for energy consultant according to HOAI (2013) and available hours for a multi-family house as described in case study 2

\begin{tabular}{|l|l|r|}
\hline Phase & Tasks & HOAI \\
\hline 1 & Definition of requirements and goals & $3 \%$ \\
\hline 2 & $\begin{array}{l}\text { Pre-dimensioning of relevant } \\
\text { construction parts and creation of } \\
\text { simulation models }\end{array}$ & $20 \%$ \\
\hline 3 & $\begin{array}{l}\text { Updating simulation models and } \\
\text { dimensioning of technical } \\
\text { equipment }\end{array}$ & $40 \%$ \\
\hline 4 & Energy performance certificate & $6 \%$ \\
\hline 5 & Refining results of phases 3 and 4 & $27 \%$ \\
\hline 6 & Supporting tendering & $2 \%$ \\
\hline 7 & $\begin{array}{l}\text { Evaluation of the offers regarding } \\
\text { the requirements }\end{array}$ & $2 \%$ \\
\hline
\end{tabular}




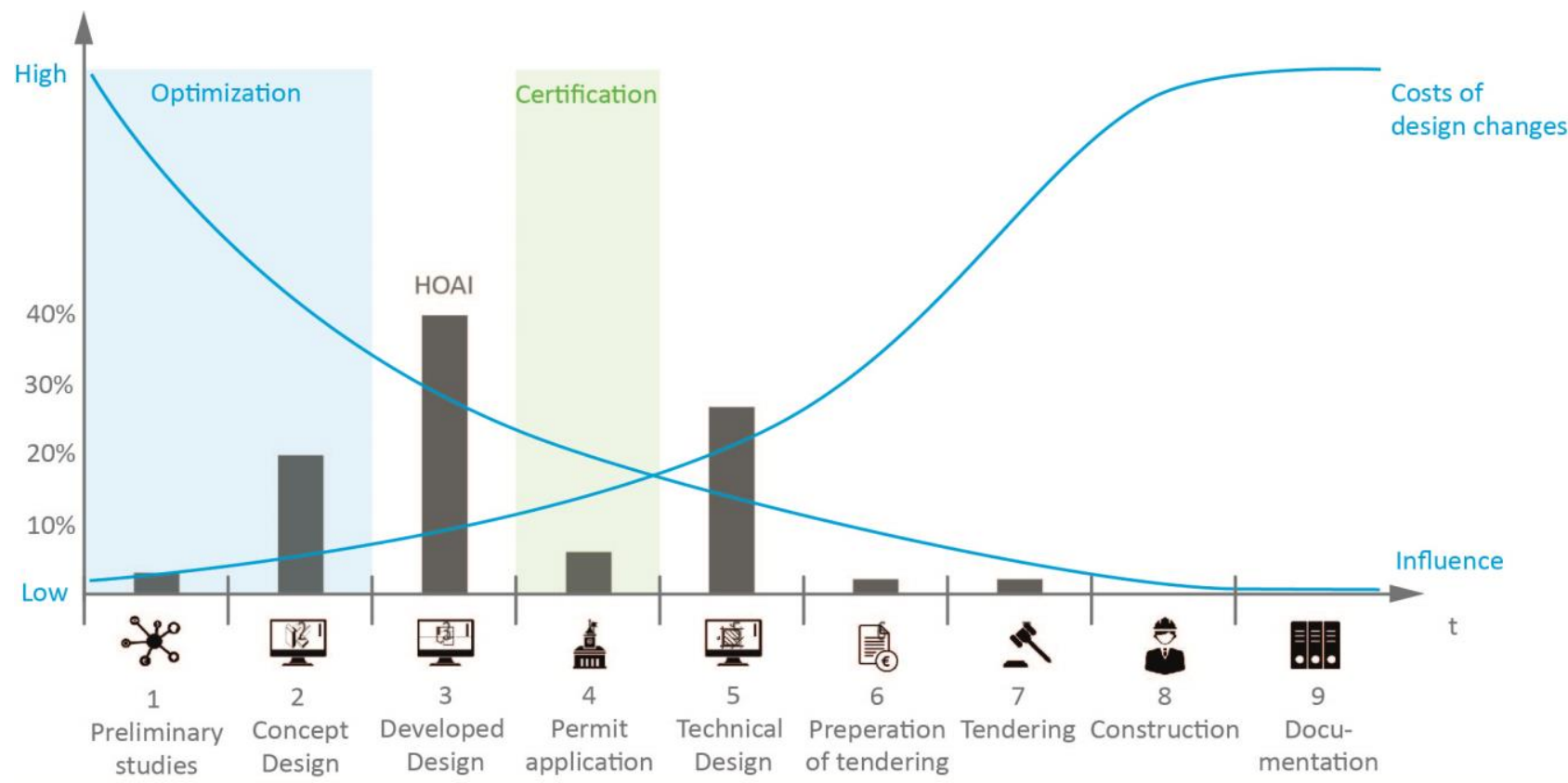

Figure 1: Design phases defined in the German fee structure for architects and engineers (HOAI 2013)

The question is why optimization of the energy performance is not carried out in early design stages and why energy consultants are not involved earlier. One problem in the German context is that the current energy performance regulation does not require improvement. The threshold that has to be met is defined by outperforming a virtual reference building with the same geometry. This means a better use of material or technical equipment is required, but passive strategies and an optimization of the building's shape do not help to meet the threshold as the reference building is also improved. As such, holistic optimization including the geometry can only be based on comparing different variants. This is rarely done in practice because it is time-consuming and expensive with current tools and not mandatory. A further main barrier towards integrated design development is the communication between architects and consultants. In most cases, architects provide 2D plans. Energy consultants then either calculate the relevant surface areas manually or use a simple 3D tool to re-draw the geometry and take-off the surface areas. Building Information Modelling (BIM) aims towards collaboration of different stakeholders based on one digital model of the building. BIM has successfully been employed to improve the collaboration between designers and energy consultants in exemplary projects, but is rarely employed in small projects. Therefore, simplified approaches using so-called early-BIM (Hollberg, Agustí-Juan, and Habert 2018) and/or parametric design approaches (Roudsari, Smith, and Gill 2013) have been developed.

This paper investigates how a design-integrated earlyBIM tool for energy pre-dimensioning based on a simple 3D model can improve the relation between architects and energy consultants and optimize the process of issuing the energy performance certificates. The insights of the two real-life case studies of employing the tool are discussed and conclusions for improvement are drawn.

\section{Existing tools with 3D interface}

To provide a structured overview of existing tools for energy assessment with a connection to a 3D geometry they are divided into four categories in the following:

A) Full BIM-based approaches: There are a number of commercial plugins for BIM software such as Revit, ArchiCAD or Allplan that receive the geometry and material information from the BIM model. There are even more approaches developed in research projects. However, they all require a BIM model with detailed information.

B) 3D surface models: A number of tools work with so-called "shoe-box" models using a 3D model made of surfaces only. Most tools provide a plugin for SketchUp, such as Sefaira, Open Studio, or TRNSYS. The same approach can also be used using simple mass models within a BIM software, for example Autodesk Insight.

C) Parametric approaches: In recent years parametric design approaches using visual programming languages have been increasingly employed. A number of plugins for the Grasshopper3D environment have been developed, e.g. Archsim, or Ladybug/Honeybee.

D) Stand-alone 3D input: In Germany, there are eight major software tools for energy performance certificates, e.g. Hottgenroth, Evebi, or ZUB Helena. Most of them provide a stand-alone 3D input for energy consultants, e.g HottCAD. These allow to import 2D plans and model a thermal model on-top of the $2 \mathrm{D}$ floor plans. 
All four approaches have the problem of not being applicable for common German architects in common projects. The BIM-based approaches require a lot of information to provide all the data needed for the energy consultant. The digital model is only developed with this high level of detail in later design stages, meaning once the BIM model is available, major design changes are costly. As such, an optimization of the geometry based on variants is impossible. 3D surface-based approaches such as Sefaira are easy to use, but they are not based on the national German codes. Therefore, the results do not provide the information whether the threshold for the building permit is met or not. Parametric approaches are successfully used by innovative design teams, but they require expert knowledge. However, the average architect does not have the opportunity to acquire the knowledge needed and stay up to date. Furthermore, the currently available plugins are not based on German codes. The stand-alone 3D input has been developed to speed up the process of inputting the geometry for energy consultants. As such, it can facilitate the process of the certification, but it is not suited to optimize the geometry, because the thermal model has to be re-drawn from scratch for each geometric variant.

This paper focusses on closing this gap by analysing the potential of simple 3D design-integrated tools for the German context without requiring a full BIM model or expert knowledge.

\section{Method}

In this paper, we follow three main steps.

1. Interviews: We interview users and potential users of the CAALA tool (both architects and energy consultants) in Germany for their requirements towards improving the collaboration between them.

2. Adaption of tool: Based on the requirements of architects and energy consultant, we adapt an existing tool called CAALA

3. Case studies: To evaluate the potential of the adapted tool towards improving the collaboration between architects and energy consultants we apply the approach to two real projects.

\section{Interviews with architects and energy engineers}

We conducted qualitative interviews with 10 energy consultants and 30 architects who are interested in using CAALA or already use the tool. We focussed on their work regarding residential buildings and on two main aspects:

1. The use of tools for energy performance calculation in early design stages

2. The collaboration between architects and energy consultants

The results confirm many findings of other researchers in other national contexts. Regarding the first aspect, most architects mention a lack of interest in energy performance from clients, which is a reason also mentioned by Alsaadani and De Souza (2016). Furthermore, most architects said the current tools are complex, which Kanters, Horvat, and Dubois (2014) mention as number one reason not to use them. In addition, architects said that they do not have the time to use the tools, which is listed as reason number three by Kanters, Horvat, and Dubois (2014). When asking why this was the case, the answers included two main explanations. First, the input is time-consuming as the tools are complex. Second, there are already many other difficulties in the planning process and energy performance is not regarded as important as budget constraints, fire safety, acoustic insulation or structural questions, for example.

Most architects were not satisfied with the collaboration with energy consultants. First, the communication with the consultants consumes a lot of time. They often do not know which information the consultants need. Second, they feel like they have to wait an unreasonable long time before they receive results. Third, there is little trust in the results due to the competence of the consultants but also due to mistrust in the German energy performance regulation (EnEV). In addition, architects often feel that energy consultants do not provide innovative solutions that support the design concept, but are limited to conventional standard approaches. As such, the results often do not provide any value in the design process for architects, but are only seen as a mandatory task. When asked how the collaboration could be improved, most architects wanted more variants and wanted the results to be delivered quicker.

The interviewed energy consultants are also not satisfied with the collaboration with architects. Most of them said they are usually hired late in the design process after all decisions have already been made by the architects and the clients. They feel they are expected to certify the building and calculate in such a way that the required performance is met. They cannot work on improving the building due to the short deadlines and small budgets. As such, they cannot fulfil their own expectations of providing a good consulting service. In some cases, the required performance threshold is not met and changes are required that cause difficulties with architects and clients. Furthermore, the output of results in their specialised software is for experts only and they find it difficult to explain the results to clients and architects.

When asked how to improve the collaboration, all energy consultants first mentioned the communication of the necessary information. On average, they spend up to $50 \%$ of the total time for a project to collect the information needed, model the building geometry and input the construction and material properties into their specific software. Most interviewed consultants use a stand-alone $3 \mathrm{D}$ input for the geometry to take-off the areas of the thermal model, but none of them use the data from the architects directly. Usually, they receive 2D plans in PDF or DWG format and sometimes additional 3D visualisations of the building. 
The interviews showed there many difficulties regarding the collaboration between architects and energy consultants. Next to the issue of a lack of trust, the main aspect is the communication of the information needed for the calculation by the energy consultants. We therefore focus on this aspect in the following.

\section{Adaption of design-integrated tool}

CAALA Software (CAALA GmbH 2018) is a plug-in for SketchUp and Rhino - tools that are commonly applied in early design stages (Kanters, Horvat, and Dubois 2014; Köhler 2016). CAALA was developed for holistic Life Cycle Assessment (LCA) of buildings in early design phases. It is based on the method of parametric LCA (Hollberg and Ruth 2016) and uses a quasi-steady state approach based on a simplification of the German standard DIN V 18599 to estimate the energy demand in the use phase (Hollberg et al. 2018). It uses a simple 3D shoebox model as input. Therefore, it provides the basis for energy demand calculation using dynamic building performance simulation, e.g. EnergyPlus or using national codes usually based on monthly energy balancing, e.g. SIA 380, DIN V 18599, ISO 52016-1. To estimate the environmental impact over the complete life cycle of a building, architects can select predefined building components from a drop down menu to save time in inputting (see Figure 2). A few parameters such as the insulation thickness can be adapted using a slider. In addition, building services including heating systems can be selected. These are linked to a component catalogue providing all information needed for the building performance simulation. The software does not replace expert software for energy demand calculation, but serves as pre-dimensioning tool to provide design guidance. In theory, the information already input in the tool can be easily transferred to the expert software of the energy consultants to avoid re-inputting of information.

The software is adapted to assess the potential of a direct link between the early pre-dimensioning tool for architects and the expert software of the engineers. It is adapted to allow for a simplified transfer using a spreadsheet in the format of the input in the energy certificate tool. Furthermore, introducing a gbXML interface allows transferring the geometry including all necessary material properties. The potential is tested by means of two real case study.

\section{Case studies}

Two case studies are used to answer the following questions:

- Does the comparison of variants provide meaningful results for architects? (case study 1)

How much time can be saved by using the interface to transfer the geometry to the energy consultant? (case study 2)

- Is the communication between architects and energy consultants improved through the use of a simple 3D model in early design stages? (case study 2)

Case study 1 consists of an office building in Berlin. The architects used CAALA in phase 1 and 2 to compare four variants modelled in Sketchup. The same material and technical equipment was assigned to all variants to compare the performance of the geometry (see Figure 3)

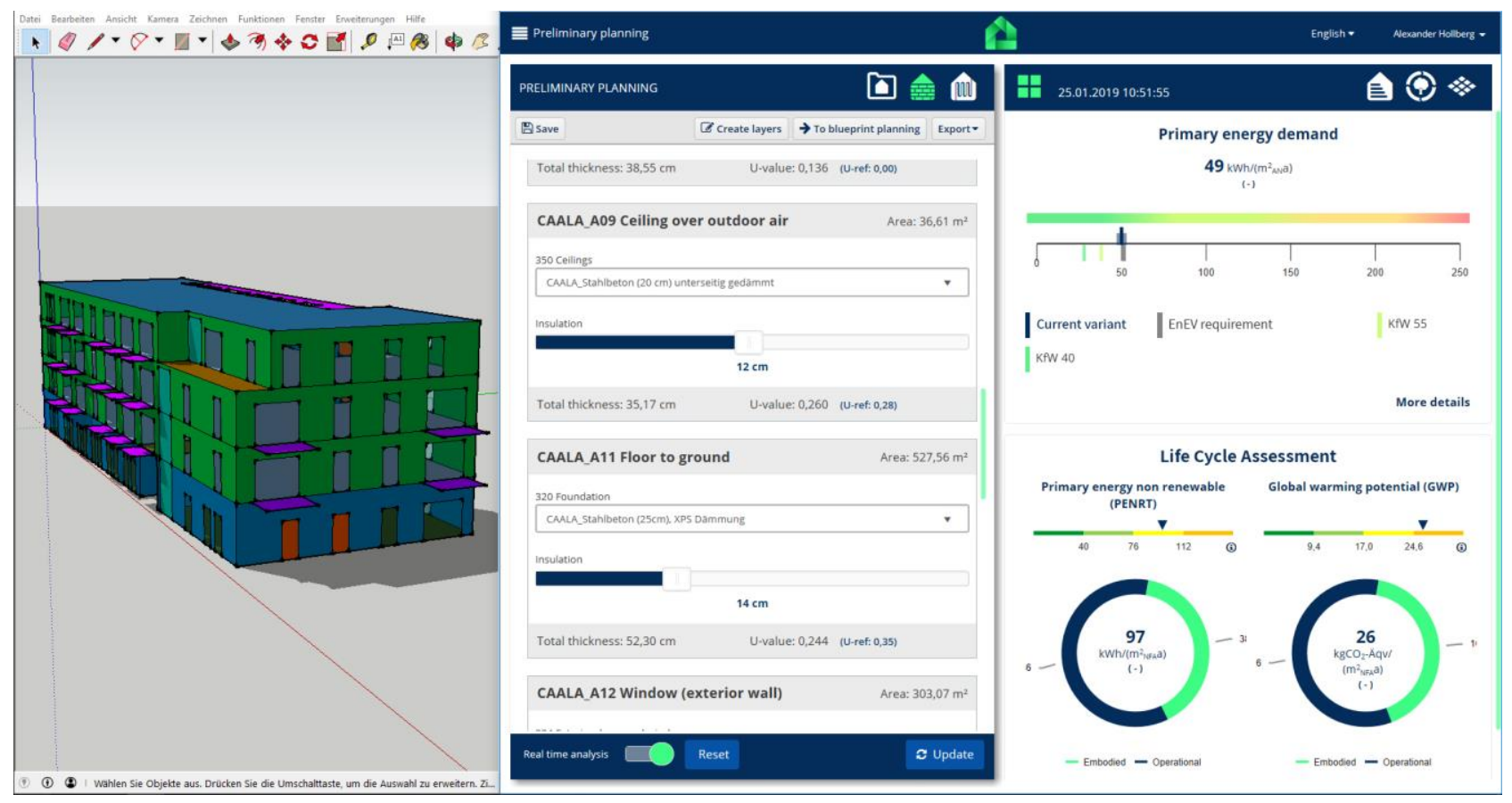

Figure 2: User interface of CAALA plugin for Sketchup 


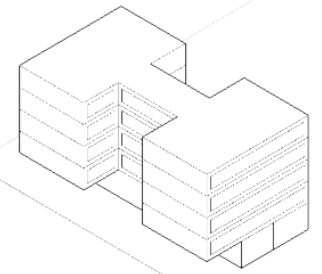

V1

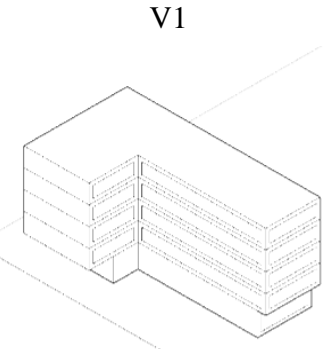

V3

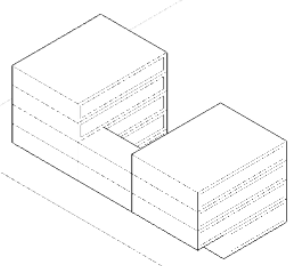

V2

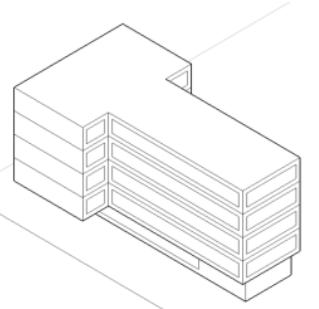

V4
Figure 3: Geometric variants of case study 1

Case study 2 consist of two multi-family houses in Berlin with a total net floor area of $3949 \mathrm{~m}^{2}$. The project developer set high requirements regarding the choice of materials and the energy performance and asked the architects to use the tool CAALA to compare different variants. Therefore, the architects used the CAALA Sketchup plugin and pre-dimensioned the building in phase 2 and 3. An energy consultant was hired in phase 4 for the energy performance certificate that is needed for the building permit application. The energy consultant modelled the building conventionally according to 2D plans provided by the architects. Furthermore, the CAALA model from the architects (see Figure 2) was used and the results are compared here.

\section{Results}

\section{Comparison of variants (case study 1)}

To compare the performance of the geometry for case study 1 only the annual heating demand is compared here. The results for the four variants are shown in Figure 4.

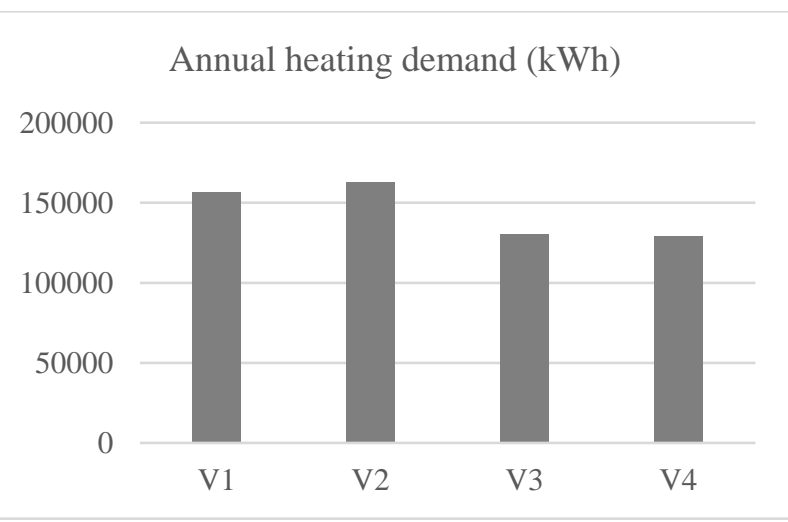

Figure 4: Comparison of the heating demand of four variants of case study 2
The difference between the best variant 3 and worst variant 2 is $20 \%$. According to the architects, this was a significant result for their further planning. This benefit is important to motivate architects to use pre-dimensioning tools in early design stages.

\section{Comparison of areas (case study 2)}

The areas of the architects and the energy consultant's model of case study 1 are compared to answer the question if the architects' model is accurate enough. The comparison shows a very good agreement (difference $0 \%$ ) for horizontal elements that can be easily taken off from 2D plans such as the Roof, Roof terrace, Access balcony, Floor above air, and Floor to ground. There was a surprisingly big difference in the area of doors of $6.7 \mathrm{~m}^{2}$. When comparing the models in detail, it became apparent that 5 doors had not been correctly transferred from energy consultant's 3D tool (HottCAD) to the EnEV tool. This error was correct and the area adapted accordingly. The comparison of the adapted areas is shown in Table 2. The difference for the total façade with $0.02 \%$ is negligible. However, the architects' model shows a smaller area for windows and doors.

Table 2: Comparison of adapted areas

\begin{tabular}{|c|c|c|c|}
\hline Element & $\begin{array}{c}\text { Area energy } \\
\text { consultant } \\
\text { (HottCAD) } \\
{\left[\mathbf{m}^{2}\right]}\end{array}$ & $\begin{array}{c}\text { Area } \\
\text { architect } \\
(\text { CAALA) } \\
{\left[\mathbf{m}^{2}\right]}\end{array}$ & $\begin{array}{c}\text { Difference } \\
\%\end{array}$ \\
\hline $\begin{array}{l}\text { Exterior wall } \\
\text { wood }\end{array}$ & 578.51 & 582.28 & -1.81 \\
\hline $\begin{array}{l}\text { Exterior wall } \\
\text { masonry }\end{array}$ & 551.25 & 548.49 & 0.50 \\
\hline Windows & 368.69 & 365.72 & 0.81 \\
\hline Doors & 57.11 & 52.80 & 7.55 \\
\hline Total facade & 1548.96 & 1549.27 & -0.02 \\
\hline Roof & 483.47 & 483.47 & 0.00 \\
\hline Roof terrace & 24.40 & 24.40 & 0.00 \\
\hline $\begin{array}{l}\text { Access } \\
\text { balcony }\end{array}$ & 56.30 & 56.30 & 0.00 \\
\hline $\begin{array}{l}\text { Floor above } \\
\text { air }\end{array}$ & 36.61 & 36.61 & 0.00 \\
\hline $\begin{array}{l}\text { Floor to } \\
\text { ground }\end{array}$ & 527.56 & 527.56 & 0.00 \\
\hline
\end{tabular}

According to the energy consultant involved in this case study, an additional benefit of transferring the architects' $3 \mathrm{D}$ model is that the energy consultant can understand the building better and quicker. Furthermore, all the material information needed is already assigned to the specific building component, avoiding phone calls or e-mails to clarify missing data.

\section{Comparison of input time (case study 2)}

The energy consultant needed 29 hours in total to provide the first simulation results and a report to the architects. 16 hours were spent on modelling of the geometry of the two buildings in HottCAD. In addition, 8 hours were 
needed to input the material information and construction details. Furthermore, 3 hours were spent in meetings and about 2 hours for sending e-mails and reports. These values are relatively low compared to an average of 80 hours for office buildings provided by Lichtmeß (2010) or 113 hours by Erhorn-Kluttig et. al. (2005)

If the energy consultant would us the architect's model, it has to be checked for plausibility. Assuming this will take 2 hours, only transferring the geometry would provide a potential to save 14 hours in this case study.

\section{Discussion and limitations}

The results of the case study showed that energy predimensioning can be of support for the design process. A typical question of architects in this context is if the predimensioning tools are accurate enough. In a previously published study we showed that the difference for the heating demand between the pre-dimensioning tool and full EnEV tools is smaller than 2\% (Hollberg et al. 2018), which is acceptable for early design phases.

In the two case studies, the communication between architects and energy consultant was satisfying for both parties. It could be observed that the simple 3D model facilitated the communication. In a way, it served as boundary object. According to Star and Griesemer (1989) "Boundary objects are both plastic enough to adapt to local needs and constraints of the several parties employing them, yet robust enough to maintain a common identity across sites. They are weakly structured in common use, and become strongly structured in individual-site use." The 3D model represents the architecture in an abstract form, but serves as a detailed model for the energy consultant. In contrast to a sophisticated BIM model, it is easy to handle and to use for all stakeholders.

Currently, the process as described here using CAALA only works for residential buildings. According to German regulations, residential buildings can be modelled as single zone models. Non-residential buildings require modelling of multiple thermal zones. The correct modelling of these is quite difficult for nonexperts (Hollberg et al. 2016). To solve this problem in the future, an autozoning algorithm as proposed by (Dogan and Reinhart 2017) that is compliant with the German energy code could be developed. Furthermore, a simplified approach for calculating non-residential buildings with a single zone as described by Lichtmeß (2010) could be used.

In this paper only two case studies were analysed. To make sure the process works in other projects, too, more studies should be carried out in the future. The architects of case study 1 were interested in trying the proposed predimensioning tool to improve their design. The results motivated them to also use it in the future. However, many interviewed architects did not show interest in testing the pre-dimensioning as they feel over-worked and do not see it as their responsibility. Therefore, these architects might only use a pre-dimensioning tool in the future, if clients ask for it as it was the case in case study 2 .

\section{Conclusions}

The interviews with architects and energy consultants showed that both groups are not satisfied with the current form of collaboration. Between the many difficulties that were mentioned, we focussed on the communication of the information needed for the calculation by the energy consultants. We assessed the potential for improvement using simple 3D surface models and an early-BIM approach in early design stages by means of two case studies.

The results of case study 1 show that comparing a number of variants provides meaningful results that support the further design process of the architects. This aspect is crucial to ensure the architects are willing to use this energy pre-dimensioning approach and invest time to model the thermal model that provides the basis for the energy consultant. The results of the case study 2 show that the architects' model is accurate enough to be used as basis for the energy certificate. Plausibility checks are needed to ensure the model quality. However, they are also needed when energy consultants use the current state of the art approach and redraw the building in a standalone 3D software. About $50 \%$ of the total input time can be saved by the energy consultant using this approach.

The proposed the early-BIM approach using simple 3D surface models provides a big potential to improve the collaboration between architects and energy consultants in Germany and countries with a similar context. This is especially true for small to mid-size architectural offices that do not have in-house experts and usually work on smaller project without an interdisciplinary design team and BIM managers.

\section{Acknowledgement}

We would like to thank Ruge Architekten, Klimagut AG and Atelier 4D for providing the data for the case studies.

\section{References}

Alsaadani, Sara, and Clarice Bleil De Souza. 2016. "Of Collaboration or Condemnation? Exploring the Promise and Pitfalls of Architect-Consultant Collaborations for Building Performance Simulation." Energy Research and Social Science 19. Elsevier Ltd: 21-36. doi:10.1016/j.erss.2016.04.016.

Bogenstätter, Ulrich. 2000. "Prediction and Optimization of Life-Cycle Costs in Early Design." Journal Article. Building Research \& Information 28 (5/6). Routledge: 376-386. doi:10.1080/096132100418528.

CAALA GmbH. 2018. "Computer-Aided Architectural Life Cycle Assessment (CAALA).” www.caala.de. 
Dogan, Timur, and Christoph Reinhart. 2017. "Shoeboxer: An Algorithm for Abstracted Rapid Multi-Zone Urban Building Energy Model Generation and Simulation." Energy and Buildings 140 (February): 140-153. doi:10.1016/j.enbuild.2017.01.030.

Erhorn-Kluttig, Heike, Hans Erhorn, and Edelgard Gruber. 2005. IBP-Bericht WB 128/2005 Evaluierung Des Dena Feldversuchs Energieausweise Für Nichtwohngebäude. https://www.delta-

q.de/export/sites/default/de/downloads/feldversuch nww.pdf.

Goos, Chantal. 2017. "Milieu-Impactbeoordeling van Gebouwen Als Leidraad Voor Een Duurzame Materiaalkeuze in Het Ontwerpproces." Master thesis (in Dutch), Diepenbeek, Belgium: Hasselt University.

Hegger, Manfred, Matthias Fuchs, Thomas Stark, and Martin Zeumer. 2007. Energie Atlas: Nachhaltige Architektur. Birkhäuser.

Hildebrand, Linda. 2014. "Strategic Investment of Embodied Energy during the Architectural Planning Process." TU Delft.

HOAI. 2013. Honorarordnung Für Architekten Und Ingenieure. http://www.aknw.de/fileadmin/user_upload/Gesetz e/HOAI_2013_AKNW.pdf.

Hollberg, Alexander, Isolda Agustí-Juan, and Guillaume Habert. 2018. "Design-Integrated Environmental Performance Feedback Based on Early-BIM." In IALCCE - The Sixth International Symposium on Life-Cycle Civil Engineering, 433-439.

Hollberg, Alexander, Marcel Ebert, Stephan Schütz, Burhan Cicek, Rainer Gumpp, and Jürgen Ruth. 2016. "Application of a Parametric Real-Time LCA Tool in Students' Design Projects.” In Sustainable Built Environment, 72-81. Hamburg.

Hollberg, Alexander, Thomas Lichtenheld, Norman Klüber, and Jürgen Ruth. 2018. "Parametric RealTime Energy Analysis in Early Design Stages: A Method for Residential Buildings in Germany." Energy, Ecology and Environment 3 (1): 13-23. doi:10.1007/s40974-017-0056-9.

Hollberg, Alexander, and Jürgen Ruth. 2016. "LCA in Architectural Design - a Parametric Approach." The International Journal of Life Cycle Assessment 21 (7): 943-960. doi:10.1007/s11367-016-1065-1.

Kanters, Jouri, Miljana Horvat, and Marie Claude Dubois. 2014. "Tools and Methods Used by Architects for Solar Design." Energy and Buildings 68 (PART C).
Elsevier

B.V.:

$721-731$ doi:10.1016/j.enbuild.2012.05.031.

Köhler, Myrta. 2016. "Rhinos, Hoppers, CADMonkeys." Competition Online. https://www.competitionline.com/de/magazin.

Lichtmeß, Markus. 2010. "Vereinfachungen Für Die Energetische Bewertung von Gebäuden." Bergische Universität Wuppertal.

Meex, Elke, Elke Knapen, and Griet Verbeeck. 2016. "Case Study Analysis of the Material Selection Process during Dwelling Design in Flanders." Conference Proceedings. In YRSB16 - IiSBE Forum of Young Researchers in Sustainable Building 2016, edited by Julie Železná, Petr Hájek, Jan Tywoniak, Antonín Lupíšek, and Kateřina Sojková, 1st editio, 240-249. Prague, Czech Republic: Czech Technical University in Prague.

Paulson Jr., Boyd C. 1976. "Designing to Reduce Construction Costs." Journal of the Construction Division 102 (4): 587-592.

Roudsari, Mostapha Sadeghipour, Adrian Smith, and Gordon Gill. 2013. "Ladybug: A Parametric Environmental Plugin for Grasshopper to Held Designers Environmentally Conscious Design.” In Building Simulation (IBPSA), 3128-3135. Chambéry, France.

Star, Susan Leigh, and James R. Griesemer. 1989. 'Institutional Ecology, 'Translations' and Boundary Objects: Amateurs and Professionals in Berkeley's Museum of Vertebrate Zoology, 190739." Social Studies of Science 19 (3): 387-420. doi:10.1177/030631289019003001.

T'Jonck, Pieter. 2013. "De Architectuur in Crisistijd in Crisis (in Dutch)." Journal Article. A+ Februari-M (240): 37-40.

UNEP SBCI. 2009. Buildings and Climate Change Summary for Decision-Makers.

Weytjens, Lieve, and Griet Verbeeck. 2010a. "Towards 'architect-Friendly' Energy Evaluation Tools." In Proceedings of the 2010 Spring Simulation Multiconference, 179:1--179:8. San Diego, CA, USA: Society for Computer Simulation International. doi:10.1145/1878537.1878724.

Weytjens, Lieve, and Griet Verbeeck. 2010b. "Towards 'architect-Friendly' Energy Evaluation Tools." Conference Paper. 2010 Spring Simulation Multiconference. Orlando, Florida: Society for Computer Simulation International. doi:10.1145/1878537.1878724. 